\title{
Retinal and Choroidal Blood Flows in Hypoxic. and Hypercarbic Newborn Lambs
}

\author{
J. ROSS MILLEY,(26) ADAM A. ROSENBERG, AND M. DOUGLAS JONES, JR. \\ The Eudowood Division of Neonatal Pulmonary Diseases, Departments of Pediatrics and Obstetrics, The Johns \\ Hopkins University School of Medicine, Baltimore, Maryland and the Department of Pediatrics, University of \\ Pittsburgh School of Medicine, Pittsburgh, Pennsylvania, USA
}

\begin{abstract}
Summary
We studied the effect of changes in the arterial tensions of oxygen and carbon dioxide on blood flow to the retinal (RBF) and choroidal (ChBF) capillary beds in 20 lambs. One to three days after placement of catheters in the left ventricle, abdominal aorta, and brachiocephalic artery, different gas mixtures were delivered to a bag enclosing the lamb's head. One group of lambs was studied at normal and low oxygen tensions while normocarbic, and another group was studied at normal and high carbon dioxide tensions while normoxic. RBF and ChBF were measured using the radioactive microsphere technique. RBF increased as $\mathrm{PaO}_{2}$ and, thus, arterial oxygen content $\left(\left[\mathrm{O}_{2}\right]_{\mathrm{a}}\right)$ fell; in contrast, $\mathrm{ChBF}$ was not related to $\left[\mathrm{O}_{2}\right]_{\mathrm{a}}$. Oxygen delivery to the capillary bed of the retinal artery (i.e., $\mathrm{RBF} \times\left[\mathrm{O}_{2}\right]_{\mathrm{a}}$ ) was independent of arterial oxygen content because the change in $\left[\mathrm{O}_{2}\right]_{a}$ was balanced by a reciprocal change in RBF. Oxygen delivery to the choroidal capillary bed, however, rose with $\left[\mathrm{O}_{2}\right]_{\mathrm{a}}$ because there was no reciprocal decrease in ChBF. Both $\mathrm{RBF}$ and $\mathrm{ChBF}$ increase as arterial carbon dioxide tension rose. Although an increase in arterial carbon dioxide tension produced an increase in $\mathrm{RBF}$ with no change in $\left[\mathrm{O}_{2}\right]_{\text {an }}$, oxygen delivery to the retinal capillaries rose. Similarly, oxygen delivery to the capillaries of the choroid rose with carbon dioxide tension. Oxygenation of retinal tissue, which depends on oxygen diffusion from both the retinal and choroidal capillary beds, may change with variations in arterial oxygen content (increase in oxygen delivered to the choroidal capillary bed) or arterial carbon dioxide tension (increase in oxygen delivered to both the retinal and choroidal capillary beds).
\end{abstract}

\section{Abbreviations}

ChBF, choroidal blood flow

$\left[\mathrm{O}_{2}\right]_{\text {as }}$, arterial oxygen content

RBF, retinal artery blood flow

RLF, retrolental fibroplasia

Among premature infants needing intensive care, there is an increasing incidence of RLF (18). This disease has been convincingly linked to excessive oxygen administration (12), but the reappearance of RLF despite careful oxygen monitoring makes it clear that the relationship to oxygen is not as simple as was hoped. Oxygen diffuses to retinal tissue from both the retinal and choroidal circulations $(2,7)$. It is necessary, therefore, to study both circulations in order to gain an understanding of factors affecting retinal tissue oxygenation.

Alterations in oxygen and carbon dioxide tension have been found to change blood flow through the retinal and choroidal circulations in the adult $(2,5,8,9,10,22,24)$. The retina is a neural tissue, and it is not surprising that the effects of oxygen and carbon dioxide on retinal blood flow are similar to those in the adult central nervous system (2). As blood flow to the newborn brain is also regulated by oxygen and carbon dioxide $(14,19)$, they are likely to affect blood flow to the newborn retina as well. Our previous study demonstrated the importance of oxygen to retinal blood flow in the sheep fetus (17). The experiments presented in this paper measure the RBF and ChBF to the capillary beds in the newborn lamb as they relate to changes in arterial carbon dioxide and oxygen tension as well as arterial oxygen content.

\section{MATERIALS AND METHODS}

Twenty lambs, aged 3-9 d, were anesthetized with pentobarbital. We placed catheters into the left ventricle (via axillary artery), the abdominal aorta (via femoral artery), and the brachiocephalic artery (via axillary artery). The catheters were then brought to the lamb's abdomen where they remained in a pouch until use. The lambs were allowed to recover for 1-3 d postoperatively.

During the study, different gas mixtures were delivered in a random order to a bag enclosing the lamb's head. Arterial oxygen tension $\left(\mathrm{PaO}_{2}\right)$ was varied by changing the inspired gas from room air to a mixture containing $6-7 \%$ oxygen and $3 \%$ carbon dioxide (to maintain constant $\mathrm{PaCO}_{2}$ ). In this way, arterial $\mathrm{PO}_{2} \mathrm{~S}$ ranging from 21-106 were obtained. Arterial carbon dioxide tension was changed by varying the inspired gas from room air to $21 \%$ oxygen and $6-9 \%$ carbon dioxide. Eleven animals were studied at normal and low oxygen tensions while normocarbic (one of these animals was studied at three different oxygen tensions). Ten additional animals were studied at normal and high $\mathrm{CO}_{2}$ tensions while normoxic. After 15-20 min of inhalation of any given gas mixture, blood samples were collected for analysis of $\mathrm{PaCO}_{2}, \mathrm{PaO}_{2}$ (Radiometer Copenhagen $\mathrm{pH} /$ blood gas monitor-Model DHM73), [O $]_{2}$ (Lex-O - -Con; Lexington Instruments, Waltham, MA), and hematocrit (microhematocrit method). The blood flow to the capillary bed of each tissue was then measured by the microsphere technique $(6,15)$ which relies on the reference sample approach (15). Over 1-2 min, one of four $\left({ }^{141} \mathrm{Ce},{ }^{85} \mathrm{Sr},{ }^{95} \mathrm{Nb}\right.$, or $\left.{ }^{46} \mathrm{Sc}\right)$ radiolabeled $15-\mu$ diameter microspheres (3M Company, St. Paul, MN) was injected through the left ventricular catheter. A reference blood sample was withdrawn from the brachiocephalic artery at a known rate beginning $1 \mathrm{~min}$ before and continuing for $1 \mathrm{~min}$ after injection. Microsphere counts in these blood samples served as references for determination of blood flows to the eyes.

After the study, the animal was sacrificed and the eyes enucleated. The eyes were dissected as described by Alm and Bill (2). The choroid and retina from both eyes of a given animal were combined, placed in preweighed vials, and weighed immediately. 
The radioactivity in each of these samples as well as the reference blood samples was determined in a gamma counter (Model 1185, Tracor Analytic, Chicago, IL). In two animals in whom $\mathrm{PCO}_{2}$ was varied, the retina was inadvertently not counted; therefore, RBF data are shown for eight rather than ten animals. The blood flow to each part of the eye was then calculated using the relationship:

$$
\text { Flow }=\frac{N_{0}}{N_{R}} \times \text { reference sample withdrawal rate }
$$

where $\mathrm{N}_{0}$, number of microspheres (radioactivity) in a given part of the eye and $N_{R}$, number of microspheres (radioactivity) in the reference sample. In all experiments $N_{R}$ contained more than 400 microspheres to minimize errors in measuring flow (6). In experiments measuring $\mathrm{ChBF}, \mathrm{N}_{0}$ was also greater than 400 , ensuring that the error in ChBF measurement was less than $10 \%$ at the $95 \%$ confidence limits (6). For measurements of RBF, however, the amount of tissue available was such that $N_{0}$ ranged from 39-666. Although organ flows calculated from such small numbers of microspheres would be expected to be more variable than flows calculated from larger numbers of microspheres, previous investigators have not found smaller numbers of microspheres to bias the relationships found (6). To ensure that no bias in our retinal flows was introduced by our use of small numbers of microspheres, we divided the RBF data depicted in Figure 1 into that determined by more or less than 200 microspheres. The two relationships thus defined were not significantly different in slope, elevation, or residual variance by covariance analysis (20). We have, therefore, shown a single line representing the combined data.

Oxygen delivery to either the retinal or the choroidal vascular beds was calculated by multiplying blood flow by the arterial oxygen content: $\mathrm{O}_{2}$ delivery $\left(\mathrm{mmol} \cdot \mathrm{min}^{-1} \cdot 100 \mathrm{~g}^{-1}\right)=$ flow $\left(\mathrm{ml} \cdot \mathrm{min}^{-1} \cdot 100 \mathrm{~g}^{-1}\right) \times\left[\mathrm{O}_{2}\right]_{\mathrm{a}}(\mathrm{mM}) \div 1000$. Analysis of covariance

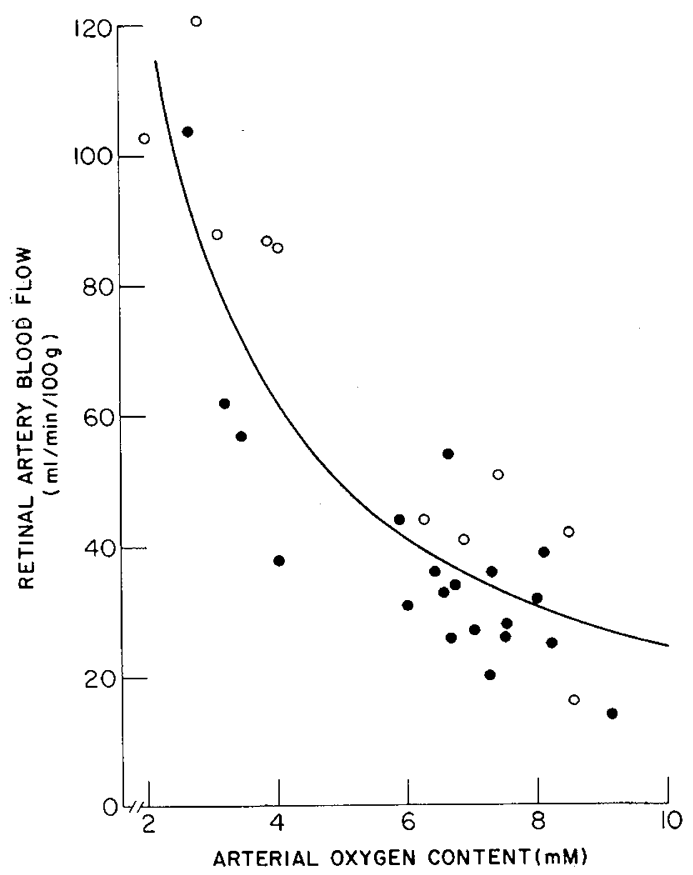

Fig. 1. The relationship between retinal artery blood flow (RBF) and $\left[\mathrm{O}_{2}\right]_{\mathrm{a}}$. Each point is the combined flow to both eyes of a single animal. $(\bullet)$, blood flows calculated from fewer than 200 microspheres and $(O)$, blood flows derived from experiments with more than 200 microspheres. Analysis of covariance of separate regressions using more than and less than 200 microspheres revealed no differences of the regressions. The line shown is, therefore, the reciprocal relationship between $\mathrm{RBF}$ and $\left[\mathrm{O}_{2}\right]_{\mathrm{a}}\left(\mathrm{RBF}=256\left[\mathrm{O}_{2}\right]_{\mathrm{a}}{ }^{-1}-1.7 ; r=0.87\right)$ using all data points.

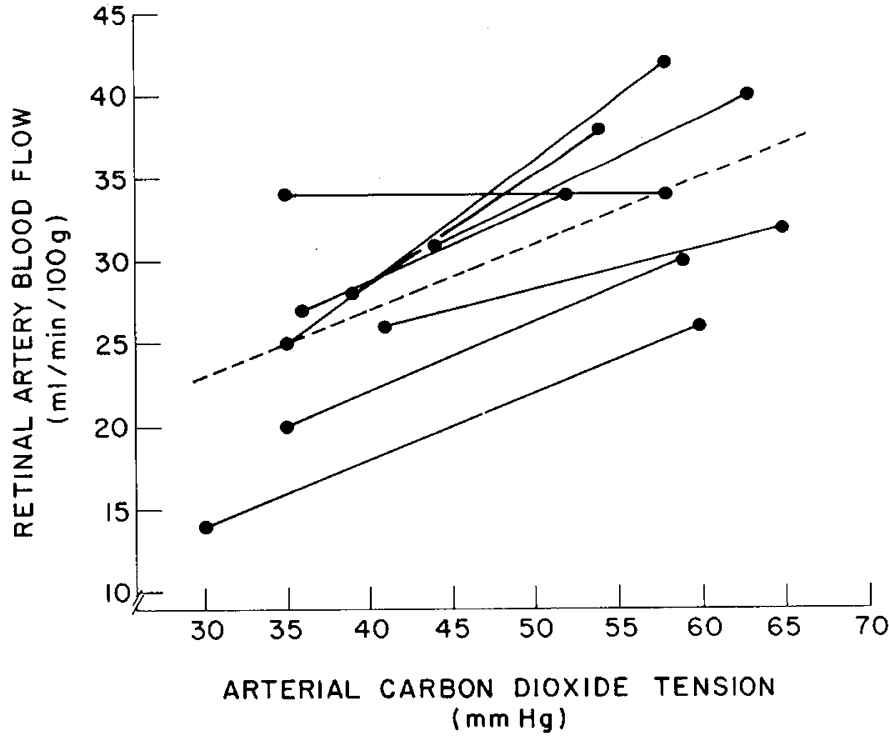

Fig. 2. The relationship between retinal artery blood flow (RBF) and $\mathrm{PaCO}_{2}$. Each point is the combined flow to both eyes of an animal. Solid lines connect separate experiments on each animal. The dashed line represents the overall relation between $\mathrm{RBF}$ and $\mathrm{PaCO}_{2}$ as defined by analysis of covariance.

was used to determine whether interanimal variation was a significant contributor to the overall variation in the dependent variable, and, if so, a weighted slope and standard error are reported. In experiments relating either retinal or choroidal blood flow to $\mathrm{PaO}_{2}$ or to $\left[\mathrm{O}_{2}\right]_{\mathrm{a}}$, inter-animal variation did not account for a significant amount of the variation in blood flow; therefore, we used standard least squares linear regression techniques following transformation of oxygen content or tension to derive each slope and its standard error (20). In addition, we included data obtained in room air from animals used in studying variation in $\mathrm{PCO}_{2}$. Comparison to the $t$ distribution was used to determine whether a slope was significantly different from zero. Comparison to the $\mathrm{F}$ distribution was used to test whether one regression was significantly better than another in accounting for changes in the dependent variable. Significance was defined as rejection of the null hypothesis at $P=0.05$. All means are shown with their standard deviation.

\section{RESULTS}

The hematocrit for the animals used in these experiments was $36 \pm 4 \%$ (SD) and ranged from $30-44 \%$. The hematocrit was not affected by either hypoxia or hypercapnia.

We expressed our measurements of RBF in the lamb as a function of both arterial oxygen content, $\left[\mathrm{O}_{2}\right]_{\mathrm{a}}$ (Fig. 1), and arterial oxygen tension, $\mathrm{PaO}_{2}$. As the scatter plots of these data suggested a nonlinear relationship, we compared reciprocal functions with the linear relationship of $\mathrm{RBF}$ and either $\left[\mathrm{O}_{2}\right]_{\mathrm{a}}$ or $\mathrm{PaO}_{2}$. The relationships between $\mathrm{RBF}$ and $\left[\mathrm{O}_{2}\right]_{\mathrm{a}}$ were significantly $(P<$ $0.005)$ better at explaining variation in $\mathrm{RBF}$ than the relationships using $\mathrm{PaO}_{2}$ as the dependent variable. The relationship of $\mathrm{RBF}$ to the reciprocal of $\left[\mathrm{O}_{2}\right]_{\mathrm{a}}$ is shown in Figure 1. During the experiments, $\mathrm{PaCO}_{2}$ (mean, $36.6 \pm 5.0 \mathrm{~mm} \mathrm{Hg}$ ) did not change.

We measured RBF in eight animals at normal and high $\mathrm{CO}_{2}$ tensions (Fig. 2). Using analysis of covariance, the following relationship was obtained: $\mathrm{RBF}=0.40\left(\mathrm{PaCO}_{2}\right)+11\left(\mathrm{SE}_{\text {slope }}=\right.$ $0.08 ; P<0.001)$. Oxygen content did not change as $\mathrm{PaCO}_{2}$ increased.

We could show no relationship between ChBF and either $\left[\mathrm{O}_{2}\right]_{\mathrm{a}}$ (Fig. 3) or $\mathrm{PaO}_{2}$. The mean $\mathrm{ChBF}$ for all neonatal lambs studied was $2393 \pm 954 \mathrm{ml} \cdot \mathrm{min}^{-1} \cdot 100 \mathrm{~g}^{-1}$. 
The variation of $\mathrm{ChBF}$ as $\mathrm{PaCO}_{2}$ changes is shown in Figure 4. Analysis of covariance showed a significant increase in $\mathrm{ChBF}$ as $\mathrm{PaCO}_{2}$ increased: $\mathrm{ChBF}=14.2\left(\mathrm{PaCO}_{2}\right)+1680\left(\mathrm{SE}_{\text {slope }}=4.6 ; P\right.$ $=0.0067)$. During this experiment, oxygen content did not change as $\mathrm{PaCO}_{2}$ increased (average change $=-0.02 \pm 0.47 \mathrm{mM}$ $P=0.91$ ).

The relationship between oxygen delivery to the individua retinal and choroidal capillary beds and both oxygen conten

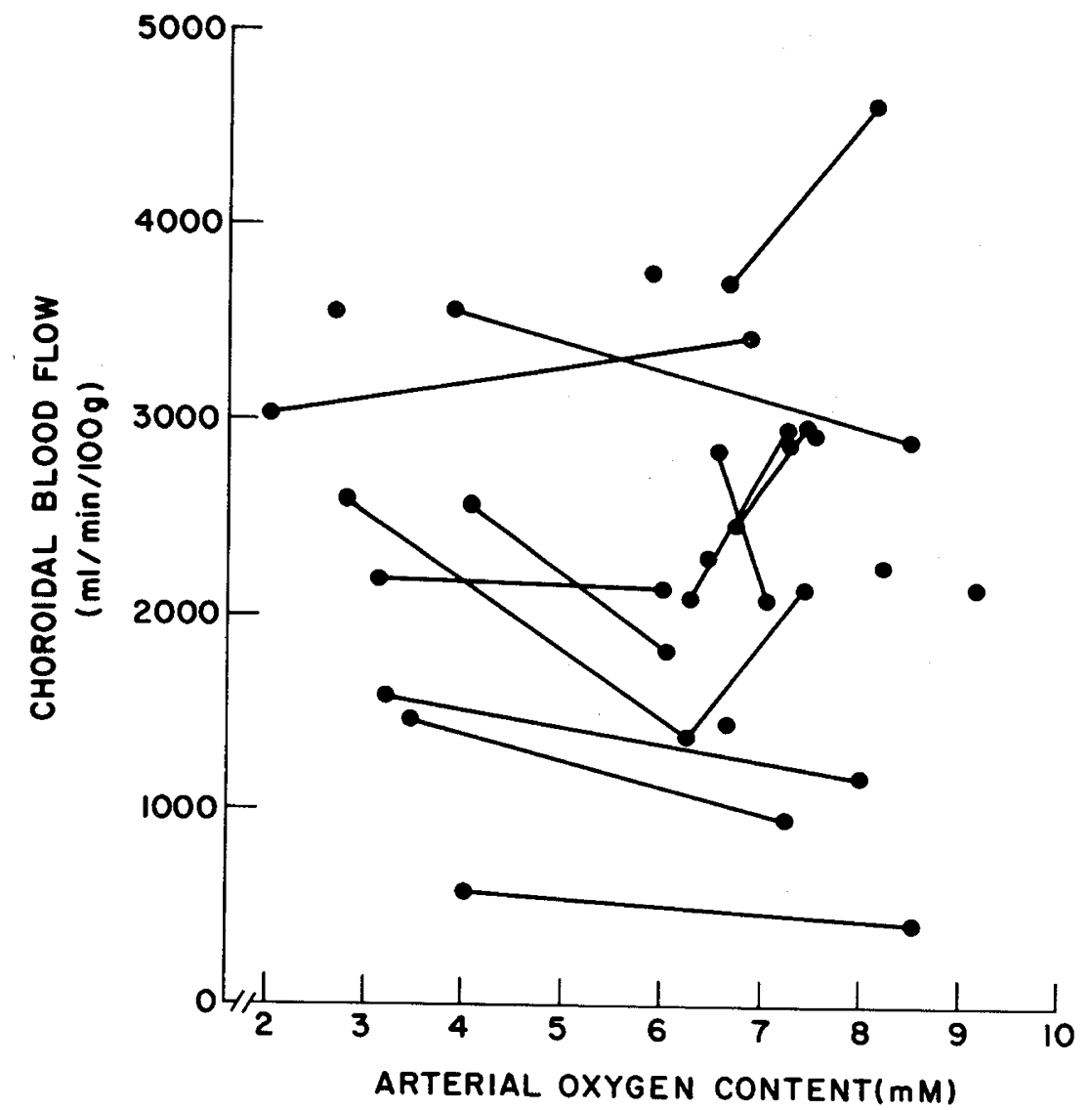

Fig. 3. Scatter plot of choroidal blood flow $(\mathrm{ChBF})$ and $\left[\mathrm{O}_{2}\right]_{\mathrm{a}}$. Each point is the combined flow to both eyes of an animal. Solid lines connect separate experiments on each animal. One animal was studied at three rather than two oxygen concentrations and these data are included.

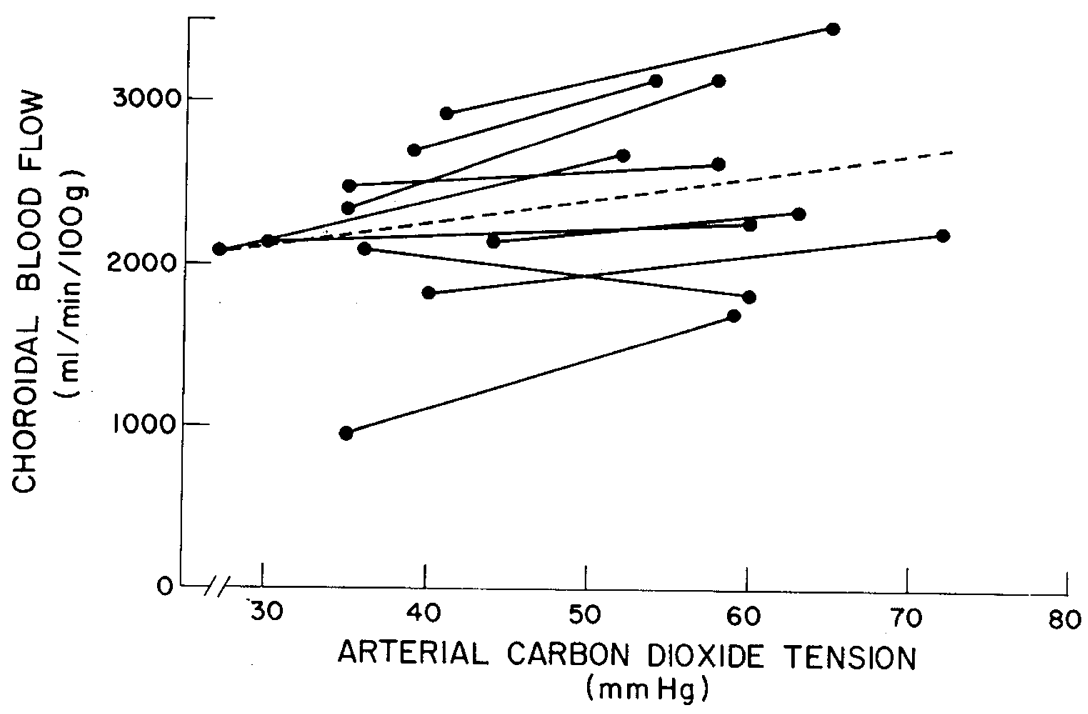

Fig. 4. The relationship between choroidal blood flow $(\mathrm{ChBF})$ and $\mathrm{PaCO}_{2}$. Each point is the combined flow to both eyes during a single experiment. Solid lines connect separate experiments in a single animal. The dashed line represents the overall relation between $\mathrm{ChBF}_{\text {and }} \mathrm{PaCO} \mathrm{O}_{2}$ as defined by
analysis of covariance. 

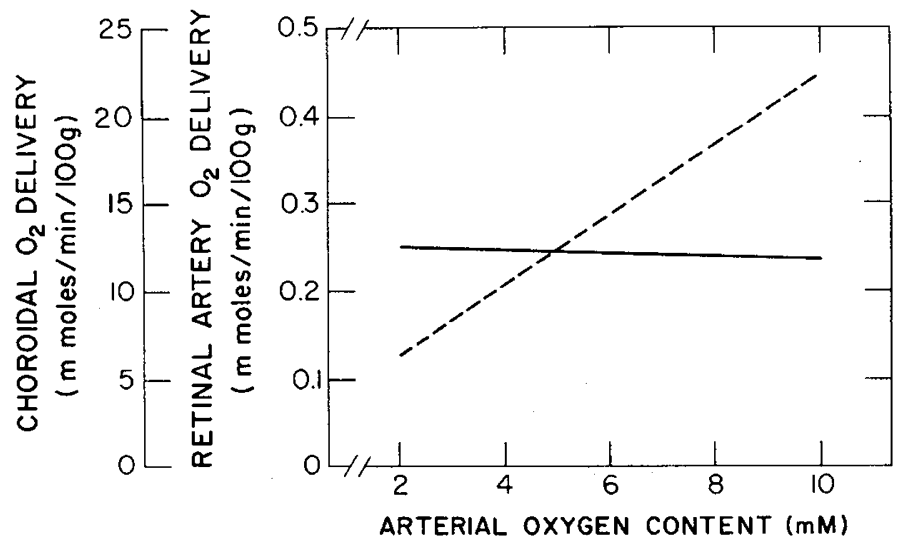

Fig. 5. The relation of retinal and choroidal oxygen deliveries to arterial oxygen content. Oxygen delivery was calculated as described in "Materials and Methods" and subjected to analysis of covariance. The dashed line represents choroidal $\mathrm{O}_{2}$ delivery $\left(\mathrm{ChO}_{2}\right.$ delivery $=2.01$ $\left.\left[\mathrm{O}_{2}\right]_{\mathrm{a}}+2.80 ; \mathrm{SE}_{\text {slope }}=0.46 ; P<0.001\right)$. The solid line represents retinal $\mathrm{O}_{2}$ delivery $\left(\right.$ Ret. $\mathrm{O}_{2}$ delivery $=-0.0012\left[\mathrm{O}_{2}\right]_{\mathrm{a}}+0.251 ; \mathrm{SE}_{\text {slope }}=0.0047$; $P=0.8$ ). The difference in scales for retinal and choroidal oxygen deliveries should be noted.
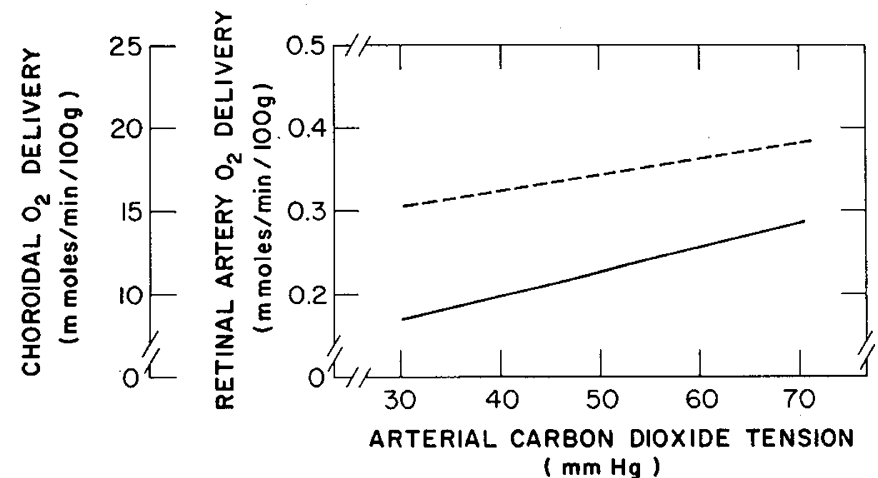

Fig. 6. The relation of retinal and choroidal oxygen deliveries to arterial $\mathrm{PaCO}_{2}$. Oxygen delivery was calculated as described in "Materials and Methods" and subjected to analysis of covariance. The dashed line represents choroidal $\mathrm{O}_{2}$ delivery $\left(\mathrm{ChO}_{2}\right.$ delivery $=0.099\left(\mathrm{PaCO}_{2}\right)+12.3$; $\left.\mathrm{SE}_{\text {slope }}=0.033 ; P=0.009\right)$ and the solid line retinal $\mathrm{O}_{2}$ delivery [Ret. $\mathrm{O}_{2}$ delivery $\left.=0.0029\left(\mathrm{PaCO}_{2}\right)+0.080 ; \mathrm{SE}_{\text {slope }}=0.00052 ; P<0.001\right]$. The difference in scales for retinal and choroidal oxygen deliveries should be noted.

and $\mathrm{PaCO}_{2}$ are given in Figures 5 and 6 . Oxygen delivery to the capillary bed of the choroid is related positively to oxygen content but oxygen delivery to the capillary bed of the retina is not (Fig. 5). Oxygen delivery to both the choroidal and retinal capillary beds is related positively to $\mathrm{PaCO}_{2}$ (Fig. 6).

\section{DISCUSSION}

The importance of oxygen in the regulation of RBF in immature animals was demonstrated in the fetal sheep (17). The present studies show results of postnatal life in the same species. After testing both $\left[\mathrm{O}_{2}\right]_{\mathrm{a}}$ and $\mathrm{PaO}_{2}$, we found that $\left[\mathrm{O}_{2}\right]_{\mathrm{a}}$ was the better predictor of $\mathrm{RBF}$. In this respect, the retinal vascular bed is like that in the brain of the fetal and neonatal sheep $(13,14)$. The reasons for a better correlation of $\mathrm{RBF}$ with $\left[\mathrm{O}_{2}\right]_{\mathrm{a}}$ than $\mathrm{PaO}_{2}$ may be that $\left[\mathrm{O}_{2}\right]_{\mathrm{a}}$ reflects both $\mathrm{PaO}_{2}$ and hemoglobin concentration. In the lamb brain these variables have independent effects on blood flow (14).

Peeters et al. (17) recently reported a reciprocal relationship between $\mathrm{RBF}$ and $\left[\mathrm{O}_{2}\right]_{\mathrm{a}}$ in the sheep fetus. They noted that the normoxic neonate had RBF similar to that of a fetus at the same $\left[\mathrm{O}_{2}\right]_{\mathrm{a}}$. Comparison of their data to ours reveals no significant difference $(P=0.53)$ between the fetus and neonate in the regression coefficient relating $\left[\mathrm{O}_{2}\right]_{\mathrm{a}}$ to $\mathrm{RBF}$. Whether the same quantitative relationship between $\left[\mathrm{O}_{2}\right]_{\mathrm{a}}$ and $\mathrm{RBF}$ would persist in the adult sheep will require further study. Previous studies of adult primates and humans show that lowered $\mathrm{PO}_{2}$ increases $\operatorname{RBF}(8,11)$ but quantitative comparisons with data in lambs and fetal sheep are not possible.

The significance of a reciprocal relationship between $\left[\mathrm{O}_{2}\right]_{\mathrm{a}}$ and cerebral blood flow in isocapnic hypoxia has been previously discussed (16): $\mathrm{O}_{2}$ delivery, the product of blood flow and $\left[\mathrm{O}_{2}\right]_{\mathrm{a}}$, is not dependent on $\left[\mathrm{O}_{2}\right]_{\mathrm{a}}$. Similarly, the delivery of oxygen to the retinal capillary bed, the product of $\left[\mathrm{O}_{2}\right]_{\mathrm{a}}$ and $\mathrm{RBF}$, is independent of oxygen content over the range of oxygen contents we studied.

The response of the retinal vasculature to changes in $\mathrm{PaCO}_{2}$ has been studied in a number of species $(2,11,21,24)$. All have found or suggested that retinal blood flow increases as $\mathrm{PaCO}_{2}$ rises. We find similar changes in the lamb. The response of the retinal vasculature to $\mathrm{PaCO}_{2}$ in lambs is apparently less than that in adult cats (2) or rhesus monkeys (24). Whether this is related to age or species is unclear. The increase of $\mathrm{RBF}$ in response to hypercapnia, like the response to hypoxia, is similar to the response noted in other components of the fetal and neonatal central nervous system $(13,19)$.

The choroidal circulation has not been well studied. Peeters et al. (17) previously noted a lack of effect of $\left[\mathrm{O}_{2}\right]_{\mathrm{a}}$ on $\mathrm{ChBF}$ in the fetal sheep, the same as our findings in the lamb. Increased $\mathrm{CO}_{2}$ tension has generally been reported to increase ChBF in adult animals $(2,25)$. We also find a significant rise in $\mathrm{ChBF}$ as $\mathrm{PaCO}_{2}$ increases in lambs. Once again, we can find no other work in immature animals or the adult sheep with which to compare our results. In the adult cat, $\mathrm{ChBF}$ increases by $38.7 \mathrm{~g} / \mathrm{min} / 100$

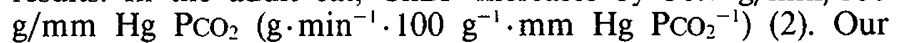
comparable figure is $14.2 \pm 4.6 \mathrm{ml} / \mathrm{min} / 100 \mathrm{~g} / \mathrm{mm} \mathrm{Hg} \mathrm{PCO}$ $\left(\mathrm{ml} \cdot \mathrm{min}^{-1} \cdot 100 \mathrm{~g}^{-1} \cdot \mathrm{mm} \mathrm{Hg} \mathrm{PCO}_{2}^{-1}\right)$. It should be emphasized that the changes in $\mathrm{PaCO}_{2}$ accounted for only $9 \%$ of the total variance in $\mathrm{ChBF}$, so other factors must play a role in its regulation. Alm and Bill $(2,3)$ found that ChBF changes with ocular perfusion pressure. We were not able to monitor perfusion pressures as we did not measure intraocular pressure.

The relationship of our experiments to the pathophysiology of RLF is indirect. The lamb, either premature or at term, is not an animal in which RLF has been found. Additionally, we have not investigated the effects of hyperoxia on ocular blood flow. Nevertheless, there are aspects of this study that may relate to RLF.

Oxygen diffuses to the retina from both the retinal and choroidal circulations. Indeed, available evidence suggests that under normoxic conditions the choroidal circulation can supply the majority of retinal oxygen consumption $(2,7)$. If oxygen is toxic to the developing retina, then factors which increase the oxygen delivered to the respective capillary exchange sites by either the retinal or choroidal arteries would increase the likelihood of damage to the susceptible retina.

When oxygen content rises, RBF falls and oxygen delivery by the retinal circulation is constant. In the choroid, blood flow does not fall as $\left[\mathrm{O}_{2}\right]_{\mathrm{a}}$ rises; thus, the amount of oxygen delivered to the choroidal capillaries increases as blood oxygen content increases. As more oxygen is delivered to the choroid, diffusion of oxygen to the retina will increase retinal tissue oxygen tension. Because oxygen delivery to both retinal and choroidal circulations increases as $\mathrm{PCO}_{2}$ rises, more oxygen is carried to these capillary beds. Again, increased retinal tissue $\mathrm{PO}_{2}$ should result from increased oxygen delivery to these capillary beds. Such an increase in local retinal $\mathrm{PO}_{2}$ has been shown directly in the adult with hypercarbia $(1,23)$. If similar physiology applies to the premature infant, increased retinal $\mathrm{PO}_{2}$ as a result of hypercarbia 
might explain a proposed relationship between $\mathrm{PaCO}_{2}$ and $\mathrm{RLF}$ (4).

\section{REFERENCES AND NOTES}

1. Alm, A. and Bill, A.: The oxygen supply to the retina. I. Effects of changes in intraocular pressure and arterial $\mathrm{PO}_{2}$ and $\mathrm{PCO}_{2}$ on the oxygen tension in the vitreous body of the cat. Acta Physiol. Scand.. 84: 261 (1972).

2. Alm. A. and Bill, A.: The oxygen supply to the retina. II. Effects of high intraocular pressure and of increased arterial carbon dioxide tension on uveal and retinal blood flow in cats. Acta Physiol. Scand., 84: 306 (1972).

3. Alm, A. and Bill, A.: Ocular and optic nerve blood flow at normal and increased intraocular pressures in monkeys (Macaca irus): a study with radioactively labeled microspheres including flow determinations in brain and some other tissues. Exp. Eve Res., 15: 15 (1973).

4. Bauer, C. R. and Widmayer, S. M.: A relationship between $\mathrm{PaCO}_{2}$ and retrolental fibroplasia (RLF). Pediatr. Res. (abstract), 15: 649 (1981).

5. Bill, A.: Blood circulation and fluid dynamics in the eye. Physiol. Rev., 55: 383 (1975).

6. Buckberg, G. D., Luck, J. C.. Payne, D. B., Hoffman, J. I. E., Archie, J. P., and Fixler, D. E.: Some sources of error in measuring regional blood flow with radioactive microspheres. J. Appl. Physiol., 31: 598 (1971).

7. Dollery, C. T., Bulpitt. C. J., and Kohner, E. M.: Oxygen supply to the retina from the retinal and choroidal circulations at normal and increased arterial oxygen tensions. Invest. Opthalmol., 8: 588 (1969).

8. Eperon, G., Johnson, M., and David, N. J.: The effect of arterial $\mathrm{PO}_{2}$ on relative retinal blood flow in monkeys. Invest. Ophthalmol., 14: 342 (1975).

9. Frayser, R. and Hickam, J. B.: Retinal vascular response to breathing increased carbon dioxide and oxygen concentrations. Invest. Ophthalmol., 3: 427 (1964).

10. Friedman, E. and Chandra, S. R.: Choroidal blood flow. III. Effects of oxygen and carbon dioxide. Arch. Ophthal.. 87: 70 (1972).

11. Hickam, J. B. and Frayser, R.: Studies of the retinal circulation in man. Observations on vessel diameter, arteriovenous oxygen difference, and mean circulation time. Circulation, 33: 302 (1966).

12. James L. Stanley and Jonathan T. Lanman (Eds.): History of oxygen therapy and retrolental fibroplasia. Pediatrics (suppl.), 57: 591 (1976).

13. Jones, M. D., Jr., Sheldon, R. E., Peters, L. L., Makowski, E. L., and Meschia,
G.: Regulation of cerebral blood flow in the ovine fetus. Am. J. Physiol., 235: H162 (1978).

14. Jones, M. D., Jr., Traystman. R. J., Simmons, M. A., and Molteni, R. A.: Effects of changes in arterial $\mathrm{O}_{2}$ content on cerebral blood flow in the lamb. Am. J. Physiol., 240: H209 (1981).

15. Makowski, E. L.. Meschia, G., Droegemueller, W., and Battaglia, F. C. Measurement of umbilical blood flow in the sheep placenta and fetus in utero. Circ. Res., 23: 623 (1968).

16. Meschia, G.: Evolution of thinking in fetal respiratory physiology. Am. J. Obstet. Gynecol.. 132: 806 (1978).

17. Peeters, L. L. H., Sheldon, R. E., Jones, M. D., Jr., and Battaglia, F. C.: Retinal and choroidal blood flow in unstressed fetal and neonatal lambs. Pediatr. Res., 14: 1047 (1980).

18. Phelps, Dale, L.: Retinopathy of prematurity: An estimate of vision loss in the United States-1979. Pediatrics, 67: 924 (1981).

19. Rosenberg, A. A., Jones, M. D., Jr., Traystman, R. J., Simmons, M. A., and Molteni, R. A.: Response of cerebral blood flow to changes in $\mathrm{PCO}_{2}$ in fetal, newborn, and adult sheep. Am. J. Physiol., 242: H862 (1982).

20. Snedecor, G. W. and Cochran, W. G.: Statistical methods. (The lowa State University Press, Ames, 1967).

21. Spaiter, H. F., TenEick. R. E., and Nahas, G. G.: Effect of hypercapnia on retinal vessel size at constant intracranial pressure. Am. J. Ophthalmol., 57: 741 (1964).

22. Strang, R., Wilson, T. M., and Johnson. N. F.: The effect of alterations in arterial carbon dioxide tensions on choroidal blood flow in rabbits. Exp. Eye Res.. 18: 153 (1974).

23. Tsacopoulos, M., Baker, R., Johnson, M., Strauss, J., and David, N. J.: The effect of arterial $\mathrm{PCO}_{2}$ on inner-retinal oxygen availability in monkeys. Invest. Ophthalmol., I2: 449 (1973).

24. Tsacopoulos, M. and David, N. J.: The effect of arterial $\mathrm{PCO}_{2}$ on relative retinal blood flow in monkeys. Invest. Ophthalmol., 12: 335 (1973).

25. Wilson, T. M., Strang, R., and MacKenzie, E. T.: The response of the choroidal and cerebral circulations to changing arterial $\mathrm{PCO}_{2}$ and acetazolamide in the baboon. Invest. Ophthalmol. Vis. Sci., I6: 576 (1977).

26. Requests for reprints should be addressed to Dr. J. Ross Milley, Department of Pediatrics, Magee-Womens Hospital, Pittsburgh, PA 15213.

27. This research was supported in part by the Hospital for Consumptives of Maryland (Eudowood), and National Institutes of Health Grant EY-02482.

28. Received for publication August $31,1982$.

29. Accepted for publication August $9,1983$.

\title{
Response of Human Newborn Lymphocytes to Alloantigen: Lack of Evidence for Suppression Induction
}

\author{
ANTHONY R. HAYWARD ${ }^{(29)}$ AND SUSAN MALMBERG \\ Department of Pediatrics, University of Colorado School of Medicine, Denver, Colorado, USA
}

\begin{abstract}
Summary
Between 1:120 and 1:180 of human newborn $T$ cells proliferate in limiting dilution cultures with allogeneic lymphocytes or with la-bearing monocytic stimulator cells. The proliferating responder cells were derived from both the OKT $4^{+}$and OKT $8^{+}$ subsets as determined by immunofluorescence and by thymidine uptake. Five to seven days after an exchange blood transfusion there was a slight increase in the percentage of OKT $8^{+} \mathrm{T}$ lymphocytes in the recipient's blood. Newborn blood also contains a population of non-T cells which proliferate in the absence of allogeneic stimulator cells. In limiting dilution cultures, the frequency of these spontaneously dividing cells was 1:3125 of mononuclear cells. Our results suggest that the newborn $T$ lym-
\end{abstract}

phocyte proliferative response to alloantigen is mature by the time of birth and they provide no phenotypic explantion for the previous report of mixed lymphocyte culture-induced suppression by newborn $T$ cells. The predominance of newborn metaphases in 2-way mixed lymphocyte cultures with adult cells (on which the previous report of suppression was based) is not seen if the non-T (stimulator) cells are irradiated. These results suggest that the data previously interpreted as evidence for suppression arose through proliferation of newborn non-T cells.

\section{Abbreviations}

AMoL, acute monocytic leukemia

HBSS, Hank's balanced salt solution 